
Malinca y traducidas por Eduardo Goligorsky, Manuel Barberá y otros traductores de literatura popular de masas. Se reflexiona sobre el papel de la censura en la canonización de obras literarias.

PALABRAS CLAVE: traducción literaria, censura y delitos de imprenta, editoriales argentinas, siglo xx.

\title{
Hacia el hondo bajo fondo: prohibición y censura de traducciones
}

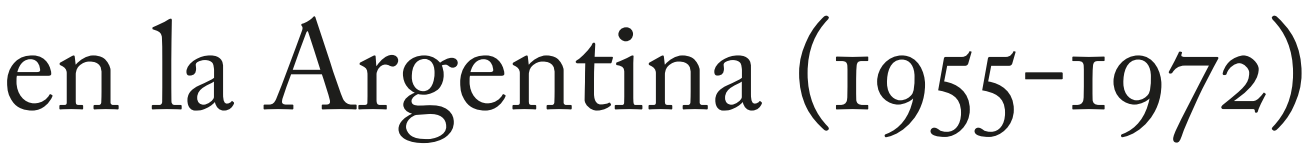

\section{Deep into the underworld: Prohibition and} Censorship of Translations in Argentina (1955-1972)

This work explores two cases of censorship of translations that occurred in the city of Buenos Aires at the end of the 1950s and analyzes the public debates generated in order to identify the

ALEJANDRINA FALCÓN

Universidad de Buenos Aires CONICET extraliterary motivations that underlie the debates aroused around the interference of political power in literary practice. The first part of the article analyzes the case of the novel Lolita by Vladimir Nabokov, translated by Enrique Pezzoni for Sur. The second part deals with the censorship of police novels, published by the Malinca publishing house and translated by Eduardo Goligorsky, Manuel Barberá and other translators of popular mass literature. It reflects on the role of censorship in the canonization of literary works.

KEY WORDS: literary translation, censorship and crimes of printing, Argentinean publishing houses, twentieth century. 


\section{INTRODUCCIÓN}

Cuando se habla de censura literaria en la
Argentina suele evocarse la represión cultural durante la última dictadura militar: la quema de libros en terrenos baldíos, las listas negras, el embargo de ediciones, el cierre de librerías, la persecución y el exilio de escritores, libreros, traductores y editores. Sin embargo, tal como ha demostrado Andrés Avellaneda (1986) en su libro pionero Censura, autoritarismo y cultura. Argentina: 19601983, la regulación de la censura cultural y la progresiva constitución de un discurso censor comenzó a gestarse mucho antes del golpe de estado de 1976. Su hipótesis es que ese discurso se consolidó por etapas de acumulación y sistematización a partir del año I960, punto inicial de su análisis:

La documentación muestra además dos fases con bastante claridad: a) una etapa en que el discurso acumula sus significados básicos, con un primer ajuste en el período 1962-1964 (gobierno provisorio de José M. Guido), y con un segundo ajuste más completo en el período 1966-1973; y b) una etapa en que el discurso se organiza sistemáticamente, desde mediados de 1974 (sobre todo durante la presidencia de María Estela Martínez de Perón) y durante el período 1976-1983, espacio donde se anudan firmemente los cabos sueltos de las dos décadas anteriores. El período de examen, pues, puede ser delimitado entre 1960 y 1983, con una etapa mayor de formación y acumulación hasta aproximadamente 1974 y otra de culminación y sistematización desde entonces hasta I983 (Avellaneda, 2006: 3I).

Por cierto, las regulaciones fundamentales del futuro discurso aparecen ya en el tramo final de la década del cincuenta. En enero de 1958, durante el último mes del gobierno de facto de
Eugenio Aramburu, se publica el decreto II5 de la Municipalidad de la Ciudad de Buenos Aires, que establece los tres criterios de calificación para libros, revistas y otros materiales impresos conforme a lo tipificado por el artículo r28 del Código Penal sobre obscenidad (Avellaneda I986: 15 ). ${ }^{\mathrm{I}}$ En este breve período, la censura operó sobre zonas precisas del sistema cultural: lo moral, lo sexual, la familia y la religión. Si bien no existió una institución que centralizara la actividad de censura, pueden identificarse algunos actores de gran visibilidad que, como el célebre fiscal católico Guillermo de la Riestra, ${ }^{2}$ se erigieron en paladines de la moralidad pública.

E1 objetivo general de este trabajo es explorar la censura de traducciones en la Argentina con el fin de despejar las motivaciones políticas, culturales y económicas subyacentes en los argumentos que alternativamente combaten y/o legitiman la intervención del poder político en la práctica literaria. Su objetivo específico es analizar dos casos de censura acontecidos en la ciudad de Buenos Aires a finales de la década del cincuenta, entre 1957 y 1959, fechas en

I Avellaneda los sintetiza: «I) material inmoral o presuntamente obsceno (venta y circulación prohibidas, más remisión de las actuaciones a la justicia para que esta examine la posibilidad de que el material incurra en lo tipificado por el artículo I2 8 del Código Penal, sobre obscenidad); 2) material inmoral (venta y circulación prohibidas); 3) materiales de exhibición limitada (venta permitida solo en locales cerrados, sin que pueda ser expuesto en la vía pública o en escaparates exteriores)» (I986: I5).

2 Si bien aquí solo se estudian casos de traducciones, el fiscal de la Riestra promovió infinidad de juicios contra escritores, impresores, actores y cineastas nacionales: Carlos Correas, Jorge Lafforgue, Germán García, Marilina Ross, Isabel Sarli y un extenso etcétera. La visibilidad del personaje no solo se evidencia en las caricaturas y bromas de las que fue objeto en revistas de humor político como Tía Vicenta, sino también en la entrada que lleva su nombre en el diccionario de personalidades del año I958/1959 editado por Kraft. 
las que fueron radicadas en sede administrativa y judicial denuncias contra editores y traductores acusados de publicar material pornográfico, obsceno o inmoral.

De acuerdo con los objetivos planteados, el artículo está estructurado en dos partes. La primera analiza el caso de la prohibición de la traducción argentina de Lolita de Vladimir Nabokov publicada por la editorial Sur, propiedad de Victoria Ocampo, a cargo de Enrique Pezzoni, oculto tras el seudónimo Enrique Tejedor. La segunda parte estudia el caso de la censura de novelas populares, en su mayoría policiales de género negro, publicadas por la editorial Malinca, y vertidas al castellano por Eduardo Goligorsky, Manuel Barberá y otros traductores de literatura popular de masas.

E1 análisis tendrá por objeto no el discurso de la censura plasmado en leyes y decretos, ya estudiado por Avellaneda, sino la discursividad generada por las partes afectadas por la censura oficial. Para ello, me basaré en encuestas a escritores y artículos polémicos publicados en revistas y libros entre 1959 y 1972. Esta base documental revela que la intervención municipal y las denuncias penales que condujeron al secuestro, prohibición y destrucción - sin juicio previo- de libros traducidos generó una réplica letrada que trascendió el reclamo por la alegada inconstitucionalidad de las medidas - el artículo I3 de la Constitución de la Nación Argentina garantiza la libertad de expresión y condena toda forma de censura previa-. Los casos de censura analizados en este artículo interesan porque dieron lugar a un debate público sobre la legitimidad del poder político para legislar en materia literaria.

\section{LOLITA EN BUENOS AIRES: REPERCUSIONES LOCALES DE UN ESCÁNDALO MUNDIAL}

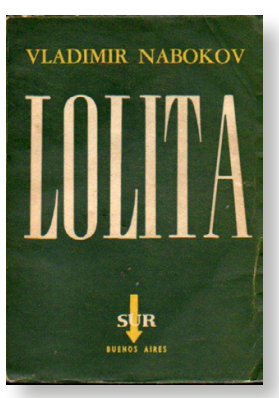

Vladimir Nabokov acabó 85 de escribir la novela Lolita en 1953 pero su historia de amor entre una niña y un hombre maduro no halló editor en Estados Unidos por esas fechas. El original fue publicado en París en I955 por Olympia Press, editora de ficción erótica y de autores como Burroughs, Miller, Genet, Durrell, Apollinaire, Queneau. Su traducción al castellano, publicada por primera vez en Buenos Aires en 1959, replicó el escándalo mundial. ${ }^{3}$ Pero no fue una pequeña editorial en los márgenes de la central industria parisina, como Olympia Press, la encargada de difundirla en castellano sino una empresa que había acumulado un importante caudal de prestigio en sus más de dos décadas de trayectoria: la editorial Sur, creada en 1933 por Victoria Ocampo. ${ }^{4} \mathrm{Si}$ bien es cierto que a partir de 1955 el grupo de escritores e intelectuales nucleados en torno a Victoria Ocampo y su revista dejó progresivamente de constituir el mascarón de proa del campo inte-

3 Sobre las condiciones de publicación de Lolita en Argentina, sus reediciones y retraducciones, véase Tullio (20I4), Libardi (2018), Conchez (2018). Las prácticas de supuesta "autocensura" en la traducción de Pezzoni, denunciadas por Hernández Bustos (200I), no corresponden a la edición de Sur. La censura de ciertos fragmentos se habría producido en la circulación posterior de la traducción ( $\mathrm{Li}^{-}$ bardi, 20I8; Conchez, 20I8), primero recuperada por Grijalbo y luego reeditada por Anagrama. La apresurada adjudicación de la práctica censora al traductor es un ejemplo de la debilidad explicativa de todo análisis de traducción que prescinda de una adecuada contextualización.

4 En 1959 la editorial Sur ya había editado el grueso de su catálogo, compuesto por obras de calidad literaria traducidas por reconocidas figuras del medio cultural (Willson 20I4). 
lectual argentino (King, I989: 207-245), la editorial Sur seguía promocionándose a sí misma como «la editorial que marca la vanguardia en el mundo de habla hispana» (Catálogo de Sur en Nabokov, 1959: 317).5 Entre mayo y junio de 1959 salieron de imprenta los primeros ejemplares de la traducción de Enrique Pezzoni, quien preventivamente había firmado con el seudónimo Enrique Tejedor. El acontecimiento se promocionó (sin mención del traductor) en el número $25^{8}$ de la revista Sur, de mayo-junio de i959. Bajo el exultante título "Apareció LOLITA», el anuncio resumía la accidentada trayectoria de la obra:

Este libro, que ha sido el más comentado por los más importantes autores del mundo entero, ha tenido sin embargo un destino adverso en sus ediciones. El gobierno francés prohibió dos veces en el curso de un año la edición de esta novela en inglés y solo a principios de este año pudo la editorial Gallimard decidirse a editarlo en francés. Reeditado en inglés en los Estados Unidos, donde se mantiene desde hace más de un año en el tope de la lista de los best sellers, su exportación a otros países ha sido prohibida, a causa del violento debate - que llegó hasta la cámara de los comunes- que el libro ha provocado en Inglaterra. Sin duda alguna, LOLITA es el caso de aquellas novelas que desafían todo esfuerzo para clasificarla e incluso describirla. UNICA EDICIÓN COMPLETA Y AUTORIZADA (Publicidad en Surn ${ }^{\circ} 258$, I959, s/p).

Ese anuncio precedía, a su vez, el artículo principal del número: un extenso ensayo de Denis de Rougemont, traducido por José Bianco, en el

5 En su estudio sobre Sur, John King revela que «aunque la editorial Sur publicó Lolita de Nabokov, y defendió su elección, Nabokov nunca recibió un centavo de regalías y acabó por retirar los derechos» (I989: 20I7) y señala que «pese a [la] acalorada defensa [de Lolita] hubo insuficientes transfusiones de la calidad de Nabokov para mantener a Sur en la primera fila de la experimentación literaria durante el sesenta» (I989: 22I). que el estudioso del amor en Occidente aludía a la novela de Nabokov como «Lolita o el escándalo» (I959: 5).

La referencia a su prohibición en otros países, la indicación de que se trataba de un best seller, las prestigiosas figuras convocadas para introducir la obra: allí estaban todos los ingredientes necesarios para producir un acontecimiento literario y comercial... y un conflicto con la ley. En la ciudad de Buenos Aires, Lolita fue atacada desde dos flancos: el municipal y el judicial. La Municipalidad de Buenos Aires la calificó de «inmoral» por aplicación de la ley municipal I260 del año I882 sobre prohibición de «escritos y dibujos inmorales» $y$, en virtud del decreto II5 de I958, determinó el secuestro de la edición alegando el potencial riesgo de caer en manos de niños o adolescentes. En julio de 1959 prohibió su venta y circulación, y fueron secuestrados ejemplares existentes en la editorial y en librerías «e incluso destruyó algunos antes de existir pronunciamiento judicial» ${ }^{6}$ (Tanzi 2006: IIo). Paralelamente, el fiscal de la Riestra «entabló una querella criminal contra los integrantes de la editorial Sur, los propietarios de los talleres impresores y el traductor de la obra, por el delito

6 Así resume Héctor José Tanzi el fallo de la Corte Suprema: «[Sur] entabló un reclamo judicial invocando la violación de la garantía del derecho de defensa en el trámite administrativo y del derecho de publicar sin censura previa. La Corte entendió por mayoría que las objeciones no entraban dentro del recurso extraordinario y que en el ejercicio del poder de policía de moralidad municipal, tenía suficiente contralor judicial en instancias inferiores. Los jueces Boffi Boggero y Aberastury reconocieron en el Estado facultades para impedir la exhibición, circulación y venta de obras inmorales como parte de ese poder de policía de buenas costumbres, aunque no se tratase de "pornografía gruesa”. Pero lo que encontraron agraviante fue la destrucción de ejemplares del libro antes que la justicia decidiese sobre la medida municipal. Con esta excepción también confirmaban la decisión administrativa ("SRL. editorial Sur c/Municipalidad de la ciudad de Buenos Aires", 27 de diciembre de i963, en F. 257-275)» (Tanzi, 2006). 
de publicaciones obscenas» (Pico Estrada, I959: Io). ${ }^{7}$ Pese al reclamo presentado por la editorial, el 27 de diciembre de 1963 la Corte Suprema ratificó la sentencia.

Claro que la prensa no tardó en hacerse eco del escándalo. Y, en septiembre de 1959 , en su $\mathrm{n}^{\circ}$ 260, la revista Sur publicó un dossier titulado «El caso Lolita». Tres tipos de documentos lo componen: una encuesta dirigida a figuras del medio literario, ${ }^{8}$ una declaración institucional de la Sociedad Argentina de Escritores (SADE) ${ }^{9}$ y una declaración colectiva firmada por medio centenar de figuras públicas: Victoria y Silvina Ocampo, Alicia Jurado, Carmen Gándara, Enrique Anderson Imbert, José Bianco, Bioy Casares, Borges, Murena, Eloy Martínez, Mujica Lainez, Ernesto Sábato, Jaime Rest, Enrique Pezzoni, secreto traductor de la obra. Ese

7 Sobre la diferencia entre «inmoralidad» $\mathrm{y}$ «obscenidad», López Castro define: «Dentro de la clasificación bipartita de las infraciones, adoptadas implícitamente por nuestra legislación, la obscenidad constituye un delito, susceptible de juzgamiento y castigo, conforme a las leyes, por la autoridad judicial competente, en tanto que la inmoralidad representa una falta o contravención, que corresponde apreciar y sancionar en el ámbito administrativo local» (I96r: II9).

8 Responden Victoria Ocampo, Juan Adolfo Vázquez, Jorge Luis Borges, Eduardo González Lanuza, Carlos Mastronardi, Silvina Ocampo, Carmen Gándara, Ernesto Sábato, María Rosa Oliver, Alicia Jurado, Guillermo de Torre, Manuel Mujica Lainez, Carlos Viola Soto, Alicia Marta Justo, Ernesto Shoo, Luis Justo, Héctor Murena, Jaime Rest, Eduardo Mallea, Enrique Pezzoni, José Blanco Amor y Virgilio Piñera.

9 La SADE se constituye en 1938 como «un organismo permanente que integrara las distintas expresiones literarias y velara por los intereses legales y económicos de sus integrantes». Conformaron la primera Comisión Directiva los escritores Leopoldo Lugones (presidente), Horacio Quiroga (vicepresidente), Samuel Glusberg (secretario) y Manuel Gálvez (tesorero). La asociación obtuvo personería jurídica el 24 de octubre de 1938 en virtud de decreto ${ }^{\circ}$ I5.664 dictado durante la presidencia de Ortíz. Entre 1959 y 196r ejercieron la presidencia Alberto Erro y Fermín Estrella Gutiérrez (véase SADE http://www.sade.org.ar/ historia.html). dossier constituye una fuente excepcional por la cantidad de opiniones que recoge y el elenco de problemas que plantea. En su conjunto, las intervenciones iluminan tres aspectos relevantes para un estudio sobre la censura de traducciones literarias en la Argentina: la existencia de una memoria discursiva de la censura literaria mundial, que legitima las obras prohibidas al inscribirlas en una noble tradición; el rechazo letrado al efecto de «bestsellerización» de las obras censuradas; y la consecuente validación de la censura aplicada a la literatura industrial surgida en el contexto de auge mundial de la cultura de masas.

\section{Censura y valor literario}

La primera pregunta de la encuesta indagaba sobre el derecho del «poder político» a ejercer la facultad de censurar obras literarias (Encuesta de Sur 1959: 45). Las respuestas fueron variadas en extensión y estilo pero bastante uniformes en cuanto al contenido - aun cuando algunos encuestados reconocían no haber leído la obra-: todas ellas objetaban la injerencia del estado en materia estética. Y varios fueron los encuestados que hicieron referencia a la tradición de obras alguna vez censuradas, prohibidas o llevadas a juicio por poderes políticos. Ernesto Sábato, por ejemplo, hizo una lista de los autores perseguidos en el pasado y consagrados por la posteridad:

Hay, por lo demás, los ejemplos tristísimos de Baudelaire, de Flaubert y de Joyce. Qué digo: está el comiquísimo caso del pastor protestante George Bernard Shaw, perseguido por un sermón sobre prostíbulos; y el ejemplo de la tierna novela de D.H. Lawrence, a quien supongo que para subrayar su predisposición ético-religiosa- Malraux llama predicador del coito (AAVV, I959c: 57). 
Carlos Mastronardi aludió a la perennidad de los valores literarios frente a la caducidad de los motivos del censor:

88
Como ocurre siempre el tiempo acabará de negar a los negadores y, corridos los años, la temida novela integrará muchas bibliotecas ortodoxas. Baudelaire y Flaubert, vilipendiados por inmorales, hoy son recibidos cristianamente por los nietos de sus implacables jueces. Estos descendientes de inquisidores conservan la fe de sus antepasados, pero también se incorporan los bienes del cautivante enemigo (AAVV, I959C: 52).

Y Mujica Lainez, cuya adaptación operística de Bormarzo sería prohibida en 1967 , reiteraba: «Flaubert y Baudelaire fueron procesados en Francia por obras maestras. Siempre sucede así. El Tiempo al fin y al cabo es el que juzga. Lolita se leerá dentro de muchos años, como Madame Bovary, como las Flores del Mal» (AAVV, I959c: 6I).

Así, el «caso Lolita» activó lo que podríamos llamar una memoria discursiva de los agravios a la república mundial de las letras, a sus aspiraciones soberanas. La injerencia heterónoma de la censura estatal en la actividad literaria, al igual que el juicio siempre interesado de los contemporáneos, actúa sobre la materialidad de las obras secuestrando ediciones, destruyendo los libros o alterando la textualidad. El juicio de la posteridad, en cambio, aparece como el juicio simbólico o literario por excelencia, garante del valor intrínseco, indicador de autonomización y universalidad. Sin embargo, el tiempo, que colabora en la canonización de las obras, también actúa sobre la heterodoxia que motiva a la censura: si Flaubert y Baudelaire pudieron ingresar, como señalaba Mastronardi, en la ortodoxa biblioteca de los vástagos del censor es porque el tiempo también aplacó aquello que sus obras tenían de revulsivo, de censurable, de límite de lo decible (aunque no borrara su recuerdo, ritualmente evocado en cada solapa, en cada prólogo o reseña). Ahora bien, a diferencia de lo planteado por Bourdieu (2002) en su conocido adagio «los textos viajan sin sus campos de producción», los textos literarios alguna vez censurados no parecen viajar en este caso sin sus contextos de producción, sino por el contrario quedar signados por la prohibición material como paradójico signo indeleble de un futuro valor universal, como revela el uso propagandístico de la censura en el anuncio de Lolita en el número 260 de la revista Sur.

Contracara de lo anterior, la censura como «factor de escándalo» también puede constituir una de las «razones del best sellen», como señala Vila-Sanjuán respecto de Lolita y El amante de Lady Chatterley: «la polémica sobre el contenido sexual del libro contribuyó de forma inequívoca a disparar sus ventas» (20Ir: II7). Ante ese efecto de bestsellerización de lo prohibido y de la censura como propaganda editorial, los encuestados en Sur reaccionaron con aprensión. En retahíla se suceden las muestras de rechazo al efecto de bestsellerización: «Confieso que lo leí con ese recelo que por anticipado me produce todo best seller», decía González Lanuza (AAVV, I959c: 50); Alicia Jurado por su parte sostenía: «si no me hubiesen pedido que contestara a esta encuesta, jamás habría leído Lolita; siento una natural aversión hacia los best sellers y mucho más cuando los rodea una propaganda basada en su presunta pornografía» (AAVV, I959c: 58). Por añadidura, argumentaron otros, la bestsellerización de la novela de Nabokov se fundaba en un malentendido: Lolita no era una obra «al alcance de todo el mundo» (Vázquez en AAVV, I959c: 48). Carmen Gándara llevó este argumento a su más claro desarrollo: 
Si la obra de Vladimir Nabokov, Lolita, no hubiera sido prohibida en varios países, no habría sido leída sino por un reducido grupo de lectores. Según se nos dice en el prólogo a la edición inglesa hecha en París, las ventas, que eran muy bajas, comenzaron a subir a raíz de la interdicción en Inglaterra y en Francia. Esto es perfectamente lógico porque la obra es poco atrayente para el gran público, pues está situada en un plano estrictamente literario y su lectura no es fácil ni amena. Casi diría que está naturalmente destinada a especialistas de la literatura (AAVV, I959c: 53).

En síntesis, la encuesta de Sur revela que la prohibición de Lolita en el Municipio de Buenos Aires dio lugar a dos representaciones en apariencia contrarias: por un lado, la censura habría contribuido al éxito comercial de libro y a su errónea conversión en best seller; por otro, la prohibición fue vista como pronóstico de su futura consagración literaria. Si ese destino de obra maestra halagaba a los defensores de Lolita, su éxito de mercado parecía resultarles incompatible con la concepción mayoritariamente sostenida según la cual la literatura era un arte destinado a minorías capaces de percibir la belleza tras la hojarasca del vil escándalo. De hecho, pese a las apariencias, los paladines de la libre circulación de Lolita estaban lejos de ser compulsivos partidarios de «la libertad absoluta e incondicional para cualquier producto impreso» (Sábato en AAVV, 1959c: 57).

\section{Peligrosas lecturas: libros baratos y censura legitima}

La segunda pregunta de la encuesta de Sur no descartaba de plano la necesidad de censura oficial sino que preguntaba por los límites y los criterios que debían regir su aplicación (AAVV, I959c: 45). Las respuestas revelan, una vez más, cierta homogeneidad: reacios al efecto best seller, a su tufillo a masividad populachera, pero firmes defensores de la autonomía de la alta literatura, de las «auténticas obras de arte» - como sostuvo Guillermo De Torre (AAVV, I959c: 60)—, no rechazaban la censura de los libros baratos que la industria editorial destinaba a los sectores populares, y que a sus ojos encarnaban peligrosas lecturas, dañosas para un público lector ingenuo, permeable... Ese fue el argumento de María Rosa Oliver:

Seducción, corrupción de menores, vicio, constituye el tema de millares de ejemplares que cualquiera puede adquirir en cualquier puesto de venta de periódicos en nuestra capital, junto a las historietas policiales en serie y otras publicaciones de pornografía disfrazada [que] son infinitamente más contaminadoras: el precio de estas publicaciones es de 5 a $\mathrm{I} 5$ pesos: el de Lolita I4O (AAVV: 58).

El precio, claro indicador del carácter popular de las publicaciones, pasaba a constituir un factor de diferenciación y aun de (dis)valor literario. En ese mismo sentido, Sábato sostuvo, citando a Orwell, que las novelas policiales de Hadley Chase constituían una forma de fascismo literario:

¿Podemos estar en forma absoluta e incondicional contra toda forma de discriminación? A mí no me parece ventajoso que un chico de diez años vea ciertos films, como no creo que sea bueno en ningún sentido (tampoco para el Porvenir de la Literatura) que un adolescente lea Otra que orquideas para Miss Blandish, ese género de libros que Orwell denominaba fascismo literario (AAVV, 1959c: 57).

El crítico y traductor Jaime Rest también registra esa zona de «literatura amorfa y anónima que ha invadido las ciudades [y que] quizá debiera ser combatida con urgencia» (AAVV, I959c: 67) pues su único propósito es «adular los 
apetitos de las grandes masas de la población y que por tanto constituye una forma de demagogia» (Rest en AAVV, I959c, 1959: 67). Sin embar90 go, en su respuesta, Rest se muestra capaz de reconocer una jerarquía de valor en el interior de los géneros y cierta calidad en el oficio literario:

[e]ntre ellas, rara vez sobresale algún nombre que merezca ser recordado; citemos Miss Blandish; como ejemplo aproximado - pero trazado con la eficacia de un escritor que por lo menos posee la calidad de su «oficio»mencionemos el capítulo final de I, the Jury de Michey Spillane. Esta producción solo es una actividad comercial que aspira a suscitar el interés de los sectores menos avisados; eso es lo que la hace tan perniciosa: trata de halagar la procacidad imaginativa de quienes conservan la ingenuidad de la juventud o de la escasa ilustración; pretende adular los apetitos de las grandes masas de población; por lo tanto, configura una forma de demagogia (AAVV, I959c: 67).

Al introducir un principio de discriminación en «la masa amorfa» de la producción literaria industrial, Rest se diferenciaba del resto de los encuestados. Con ello anunciaba algunos de los argumentos vertidos luego en sus ensayos sobre literatura y cultura de masas, y en particular sobre «literaturas marginales» (I979: 85-87). Su posterior labor como traductor, asesor literario y director de colecciones de literatura extranjera en editoriales comprometidas con la democratización de la cultura, como el Centro Editor de América Latina, lo llevaría a matizar la condena de los géneros populares y aun hallarle un sentido de clase:

[Fi]guras representativas de la actividad humanística - miembros egregios de las «minorías selectas»- suelen sentarse en nuestros días a llorar junto a los ríos de Babilonia,

en memoria de la irrecuperable Sión. Es justo preguntarse si estos gemidos son sinceros o si, en realidad, son no tanto lamentaciones por los preciados bienes de la inteligencia cuyo menoscabo se denuncia cuanto el clamor de algunos grupos que están perdiendo autoridad a causa de su propia inercia (Rest 1966: 25).

Ahora bien, de la encuesta se desprende otra clave para interpretar el caso: el efecto de bestsellerización emanado de la censura produjo una zona de fricción entre dos públicos, entre dos tipos de lectores al parecer bien diferenciados, como explicaba Pezzoni con picardía:

Cosa extraña, Lolita da placer a todos: el escritor profesional encuentra en ella una prosa que es una serie de rarezas; el lector de novelas psicológicas, una situación desgarradora; el aficionado a las escenas eróticas, dos o tres descripciones de insólita precisión. Por una vez, la masa anónima consumidora de best sellers se roza con los intelectuales (AAvv, 1959c: 68).

Por supuesto, no todos vieron con buenos ojos ese roce entre productores de bienes culturales raros — «lectores lúcidos y conscientes de la ficción literaria» (Pezzoni en AAVV, I959c: 69) y la «masa anónima consumidora» de la literatura industrial de gusto dudoso. E1 documento de la Sociedad Argentina de Escritores (SADE) consignado al final del dossier hace explícita esta incomodidad y exhibe la voluntad de diferenciarse asumiendo una política institucional propiciadora del control de los impresos de corte popular y tenor sexual:

La Sociedad Argentina de Escritores, consecuente con las declaraciones formuladas en el Iv Congreso de Escritores, realizado en Mendoza, propicia una campaña de limpieza contra la torpeza pornográfica que ensucia 
los kioscos de publicaciones, pero en modo alguno puede admitir que ello sirva de pretexto para la calificación arbitraria de obras que por sus calidades artísticas, como en el caso de Lolita, quedan por ese solo hecho fuera de tan infamante designación (AAVV, I959a: 73).

Al hacer suya la propuesta de una «campaña de limpieza» del material considerado pornográfico, la declaración de la SADE coincidía peligrosamente con el discurso del censor, a la sazón encarnado en la figura del fiscal Guillermo de la Riestra y los comisarios de la Sección de Moralidad con los que solía actuar.

\section{CENSURA Y LITERATURA DE MASAS}

«Cómo llamaría esta campaña iniciada por usted de lucha contra la pornografía?», preguntaba Pirí Lugones en una entrevista realizada a Guillermo de la Riestra en noviembre i96o: «No la llamaría campaña. La llamaría, simplemente, cumplimiento de una obligación. La ley I893, artículo II8, inciso I ${ }^{\circ}$, impone a los fiscales la obligación de denunciar las publicaciones obscenas», respondía «la figura más discutida de Buenos Aires», impulsor de procesos judiciales contra editores, impresores y traductores de obras presuntamente obscenas o inmorales de origen mayoritariamente anglosajón. Interrogado por los casos de libros denunciados por obscenidad, de la Riestra enumeraba:

Aparte de los libros que pertenecen a los bajos fondos, como los de las colecciones Coral, Cobalto, etc., hablando de literatura, Lolita y El reposo del Guerrero. [...] Para El reposo del guerrero todavía no hay sentencia. Ha habido muchas chicanas y al traductor no se lo ha podido procesar por estar en Europa. El asunto de Lolita está en trámite. No está en librería solo por disposición municipal. [M]e estoy refiriendo a la literatura y no a las obras de pornografía que se venden en los bajos fondos, y que son traducciones de novelas pornográficas norteamericanas (de la Riestra citado en Lugones, I960:).

Ahora bien, es hora de preguntarnos ¿qué era exactamente esta producción condenada por actores tan variados como un fiscal de la derecha católica y una revista como Sur, identificada por su liberalismo humanista y cierto ecumenismo que le permitía acoger en sus filas muy diversos perfiles ideológicos?

\section{Sexo, violencia y detectives}

Entre la década del veinte y la del cincuenta del siglo $\mathrm{XX}$, se multiplicaron a escala mundial los emprendimientos comerciales vinculados con la edición de literatura popular de masas. Si bien desde fines del siglo XIX existía un mercado de folletines, folletos y novela de aventuras, gótica, sentimental, policial o de proto ciencia ficción, en ese lapso el fenómeno llegó a su auge, tanto en lo relativo al número de obras publicadas como a su tirada y a su relevancia literaria y plástica (Abraham, 20I7: 37).

En efecto, tras la Primera Guerra, confirma Martin Lyons (2012), el mundo de la edición se vio confrontado a la emergencia de nuevos modos de entretenimiento masivos - como la radio, el cine y la prensa diaria - con los que debía competir. Este y otros factores impulsaron el desarrollo de prácticas editoriales destinadas a maximizar la competitividad del libro: se idearon nuevos canales de venta supermercados o quioscos-, nuevos modos de circulación - clubes de lectura, escuelas, bibliotecas-, novedosas técnicas de publicidad e inéditas campañas promocionales, que vinieron a apuntalar los cambios derivados de la ampliación del público lector en virtud de la democratización de la educación primaria y secundaria: 
[L]os libros que llegaban ahora a mano de los lectores eran productos industriales de consumo. Estaban encuadernados industrialmente, tenían tapas de atractivos colores y los tipos de letra resultaban muy familiares, ya que se elegían a partir de un conjunto cada vez más reducido de opciones a medida que la producción se iba estandarizando (Lyons, 2012: 366).

El avance de una literatura de masas constituyó un fenómeno mundial irradiado desde los Estados Unidos. El mercado del libro europeo se vio inundado de obras de pulp fiction, que contribuyeron a propagar su influencia cultural. Esta avanzada suscitó, entre los intelectuales europeos, una fuerte reacción contra la «invasión estadounidense» pero también favoreció a numerosos editores que «sabían que, en un mundo ferozmente competitivo unos pocos títulos de taquilla habrían de financiar títulos más literarios y experimentales» (Lyons, 20I2: 368). ${ }^{\text {Iо }}$

En la Argentina, las más destacadas editoriales de literatura de masas fueron Tor, Acme, Molino y Abril, todas ella partícipes de una política del libro barato. En la estela de estas cuatros empresas, "numerosas editoriales realizaron una importante contribución a la literatura de masas nacional: Calomino, Bo-Si, Buchieri, Rubio \& Cía., Sarmiento Casa Editora, Alfredo Angulo, Difusión, Octrosa, Malinca, Littere, S.E.L.A, Crítica y Empresa Editora de La novela semanal y El suplemento» (Abraham 20I7: 39-44).

El auge de la literatura de masas favoreció a un sector del empresariado volcado a la edición de calidad que, como Gaston Gallimard en Francia, vio en el filón popular un negocio viable para engrosar las arcas. Tal fue el caso del

ro Lyons cita como ejemplo la boutade del editor francés Gastón Gallimard: «Si puedo editar poesía que nadie entiende, es gracias a mi serie de novelas de detectives» (2012: 368). exiliado catalán Joan Merli Pahissa, fundador de Poseidón, una editorial de prestigio dedicada a la alta literatura y a libros de arte y arquitectutra. Al advertir las cifras de venta de la literatura de masas, Merli creó una empresa paralela a Poseidón, llamada Malinca. Durante la década del cincuenta y del sesenta, Malinca difundió colecciones de bolsillo, como Débora, Espionaje, Cobalto, Nueva Pandora (la Pandora original fue una colección de Poseidón dedicada a los clásicos, y que en su última etapa había incorporado títulos policiales) y Nueva Linterna (en este caso la Linterna original fue una colección chilena publicada por Zigzag). A través de estas colecciones, en su mayoría dedicadas al género policial, arraigó en el Río de la Plata la propuesta de la novela dura, en particular la vertiente negra de sexo y sadismo cultivada por autores como Mickey Spillane, Peter Cheyney y James Hadley Chase. Esas colecciones no solo se nutrían de traducciones sino también de materiales redactados por especialistas argentinos que firmaban con seudónimos de origen anglosajón (citado en Lafforgue y Rivera, I996: 23).

Esta era la literatura de los «bajos fondos» que el fiscal de la Riestra y los funcionarios municipales consideraban obscena, equiparándola con publicaciones extranjeras de corte netamente pornográfico que también circulaban en quioscos de diarios y revistas. Entre esas novelas policiales de sexo y violencia se hallaban: $I$, the Jury de Michey Spillane, traducida por Manuel Barberá, y La carne de la orquidea de Hadley Chase, traducida por Goligorsky. ${ }^{\text {II }}$

II Cultivador de literatura de género - ciencia ficción y terror-, ensayos políticos y traductor del inglés, la trayectoria de Goligorsky está estrechamente vinculada con la traducción de género policial y con la escritura seudónima en Argentina y en España, donde se radicó en I976 (Falcón, 20I8). En I952 Goligorsky inicia su carrera como traductor de historietas del King Features Syndicate y más tarde comienza a traducir para la mítica colección 

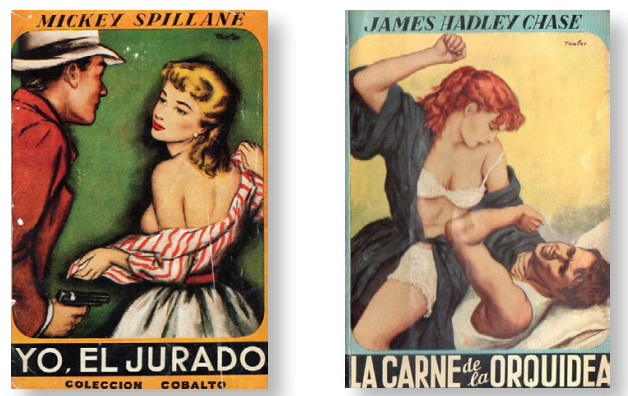

En noviembre de 1957 de la Riestra entabló juicio por el delito de publicaciones pornográficas contra el editor Joan Merli y contra Golirgorsky, como traductor, quien fue sobreseído en marzo de 1959 (Goligorsky, comunicación personal, agosto de 20I8). Además de las novelas de Spillane y Chase, mencionadas por los encuestados de Sur, de la Riestra, en combinación con un inspector de la Sección de Moralidad de la Municipalidad de Buenos Aires que tenía autoridad para secuestrar y prohibir libros y revistas, procuró impedir la circulación de obras de David Goodis, Bill Ballinger, Charles Williams y Gil Brewer, todos ellos autores de novelas policiales «duras». Cuando Goligorsky, escritor y traductor, solicitó apoyo gremial a la SADE, de la que era socio, la institución le dio la espalda. En entrevista con Jorge Lafforgue, el traductor recordaba «los escrúpulos y reticencias de la Sociedad Argentina de Escritores frente a un juicio por obscenidad promovido a raíz de

\footnotetext{
Rastros, creada por la editorial Acme de Modesto Ederra en 1944. En la década del sesenta, incursionó en la escritura seudónima de thrillers, práctica al parecer motivada por el conato de censura cuando trabajaba para Malinca, y por el escaso prestigio de que por entonces gozaba el género. Desde entonces, publicó más de veinte novelas policiales con distintos seudónimos: Roy Wilson, James Alistair, Dave Target, Mark Pritchart, Ralph Nichols, Ralph Fletcher, Mitch Collins, Buró Floyd, Dave Merritt y Lee Arriman (Lafforgue y Rivera 1996: 24).
}

cierta traducción de Mickey Spillane» y añadía: «Tengo muy presente también que, cuando en Cobalto, apareció La carne de la orquídea de Hadley Chase, se inició un proceso contra el nadie abrió la boca» (en Lafforgue, 1996: 24). Según Goligorsky, «quizá escandalizara más a tan venerable institución el carácter "marginal" y "consumístico" de esa literatura que la evidente cuota de sexo y violencia del texto impugnado» (en Lafforgue, 1996: 24).

El descargo del traductor acusado no fue tan inmediato como el descargo de Sur. Llegó en 1972, bajo la forma de un provocador ensayo publicado por la editorial Granica, en la colección Libertad y Cambio, dirigida por Goligorsky: Contra la corriente. Guía de mitos, tabúes y disparates para escépticos, herejes e inconformistas. En el capítulo "Los guardianes de la moral ajena», el autor criticaba a los defensores de una libertad de prensa parcial. Tres son los argumentos de Goligorsky que pueden ponerse en diálogo con las intervenciones del dossier Lolita:

I. Contra la censura no basta con ampararse en la noble tradición de autores prohibidos y luego consagrados; la defensa de la libertad de expresión y el derecho al consumo de cualquier material impreso ha de ser total:

Naturalmente, uno de los argumentos favoritos de los enemigos de la censura consistía en citar los títulos de los libros y los nombres de los autores que, luego de haber sido acusados de inmorales, ingresaron a la categoría de clásicos. Aristófanes, Defoe, Rousseau, Voltaire, Balzac, Baudelaire, Zola, Hemingway, Dreiser, Sinclar Lewis, Joyce, Lawrence, Henry Miller y Nabokov, entre otros, pasaron por esta experiencia. Sin embargo, como vemos, hoy ya no se reivindica solo el derecho a divulgar libremente aquellas obras de arte que 
ofenden el gusto o los prejuicios de determinados sectores, sino también el derecho de los adultos a consumir materiales que merecen, sin atenuantes, el calificativo de pornográficos (Goligorsky 1972: 187).

2. Con su voluntad de distinción, el escritor que sacraliza la (alta) literatura resulta funcional al discurso del censor:

Con el solo fin de satisfacer la vanidad de su oficio facilita armas a los censores, sin ofrecer ninguna prueba concreta de la influencia de la palabra, influencia en la que tanto hincapié hacen sus artesanos más pulcros y sus enemigos más encarnizados (I972:1980)

Los patrocinadores de la censura suponen que la palabra, la imagen y el arte en general, ejercen su influencia mágica, deletérea, sobre tres grandes ámbitos de la vida humana: el del sexo, el de la violencia y el de la ideología, y que dicha influencia es autónoma de los demás factores concomitantes (1972:183).

3. Es falaz el argumento, sostenido por los críticos de los medios de comunicación de masas, según el cual las escenas de sexo y violencia predisponen a los lectores jóvenes o inexpertos a desarrollar conductas violentas y aun delictivas; tan solo constituye, dice Goligorsky, un modo de justificar discursivamente la voluntad de «control, la censura o el simple y llano silenciamiento", de ahí que las habituales invectivas contra la industria cultural se adapten rápidamente a la particularidad de cada nuevo medio emergente; sin embargo, concluye, esa creencia es tan indemostrable como ingenua:

Quienes pretenden implantar la censura para evitar que esa minoría que se halla "previamente dispuesta a infringir la ley» pierda sus últimas inhibiciones, no solo coartan los derechos de la mayoría y juzgan la sensibilidad de esta utilizando patrones anómalos, sino que además lo hacen en aras de una empresa anticipadamente condenada al fracaso: la sociedad es rica en testimonios de violencia, brutalidad e injusticia mucho más reales y estimulantes que los que se desprenden de las series de televisión, y los criminales en ciernes no necesitan inspirarse en Mike Hammer o Los Intocables (1972: 194).

Así, con esta referencia final a Mike Hammer - el detective creado por Mickey Spillane en $I$, the Jury-, Goligorsky cerraba el capítulo evocando, sin mencionarla, la arremetida legal contra Malinca a finales de los cincuenta.

Por una de esas incongruencias de la vida asociativa, o por las vueltas de la historia institucional, en 1975 Eduardo Goligorsky recibió por su ensayo Contra la corriente. Guía de mitos, tabúes y disparates para escépticos, herejes e inconformistas la «Faja de Honor de la Sociedad Argentina de Escritores» en el género ensayo, premio anual con que esa institución reconoce hasta el día de hoy a sus miembros.

\section{CONCLUSIONES}

Para concluir este trabajo, propongo reflexionar sobre las proyecciones en el tiempo de las traducciones prohibidas aquí estudiadas.

Los indicadores editoriales, explica Lafforgue (1996: 26-27), revelan que la década del sesenta fue un momento de auge para la novela negra en la Argentina, un período en que se desarrollaron proyectos editoriales destinados a importar sus principales corrientes y referentes a fin de crear un espacio para la producción local; para ello el género debía ser prestigiado, literaturizado, librado de los prejuicios letrados que lo condenaban al bajo fondo de la sub-literatura. Entre I962 y I969 algunas editoriales incluyeron 
representantes del género negro en sus catálogos; la colección Los Libros del Mirasol de Fabril Editora, por ejemplo, tradujo a Chandler, Hammett y Ross MacDonald; incluso El Séptimo Círculo de Emecé, orientada por Borges y Bioy al policial de enigma inglés, integró a su selecto catálogo las obras de James Hadley Chase. Corolario de este auge de los duros fue la creación de la Serie Negra dirigida por Ricardo Piglia para Tiempo Contemporáneo. Casi todas las traducciones fueron escritas en un fluido rioplatense por traductores más o menos ocasionales que garantizaron la larga vida porteña del género -Floreal Mazía, Rodolfo Walsh, Estela Canto, Pirí Lugones, el propio Piglia y algunos más-. Así, los autores de novelas de género negro vieron cumplido, en el mercado del libro hispanohablante, el destino reservado a los autores malditos, prohibidos y censurados: Hammett, Chase, el Mike Hammer de Spillane, todos ellos ostentan hoy la categoría de «clásicos del género», cuando no la de «clásicos» sin más. Por cierto, no sabemos cuántos recuerdan hoy sus pasados conflictos con la ley argentina.

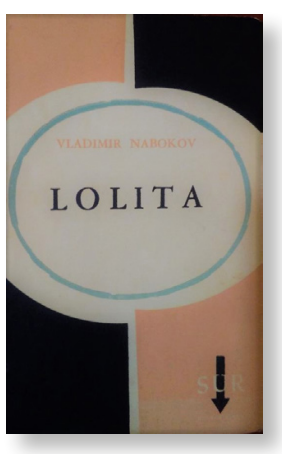

Otro fue el recorrido de Lolita. En I96r la editorial Sur pudo volver a editar la novela, sin cortes, pero en nueva imprenta, con nuevo formato, nuevo diseño de cubierta e inscripta en una serie numerada. El pie de imprenta advertía «Prohibida su venta en el Municipio de Buenos Aires». En 1975 Grijalbo adquirió la traducción de Pezzoni y la reeditó con recortes significativos; en 1986 Anagrama reutilizó la edición de Grijalbo, reprodujo con fidelidad sus olvidos pero añadió de propia cosecha toques españoles al sudamericano acento de Enrique Tejedor (Libardi 2018). Ese fue el destino de la primera Lolita argentina. Como revelan recientes polémicas, sigue trajinando su escándalo por el mundo.

RECIBIDO EN SEPTIEMBRE DE 2019

ACEPTADO EN FEBRERO DE 2019 VERSIÓN FINAL DE JUNIO DE 2019

\section{REFERENCIAS BIBLIOGRÁFICAS}

AAVV (1959A), «Declaración de la SADE», Sur, 260, sep.-oct., 72-73.

AAVV (1959в), «Declaración de un grupo de intelectuales", Sur, 26o, sep.-oct., 73-74.

AAVV (1959c), «Encuesta de Sur. El caso Lolita», Sur, 260, sep.-oct., 45-72.

Авraham, Carlos (20I7): «La literatura de masas». En: La editorial Acme. El sabor de la aventura. Buenos Aires: Tren en Movimiento.

Avellaneda, Andrés (2006): «E1 discurso de represión cultural (1960-I983)», Revista Escribas (Escuela de Letras/Facultad de Filosofía y Humanidades, UNC), 3, 3-43.

Avellaneda, Andrés (I986): Censura, autoritarismo y cultura: Argentina 1960-I983 (tomo I y II), Buenos Aires: CEAL.

Bourdieu, Pierre (2002): «Les conditions sociales de la circulation internationale des idées", Actes de la Recherche en Sciences Sociales, 145, 3-8.

Conchez Silva, Eugenio (2018): «Censura y traducción: malentendidos en torno a la Lolita de Pezzoni», en: V Coloquio «La traducción literaria. Paradojas de lo (im)posible», Facultad de Ciencias Humanas, Universidad Nacional de La Pampa, I6 de marzo de 2018.

De Rougemont, Denis (1959): «Nuevas metamorfosis de Tristán», trad. José Bianco, Sur, 258, mayojunio, I-2I.

Falcón, Alejandrina (2018): Traductores del exilio. Argentinos en editoriales españolas: traducciones, escrituras por encargo y conflicto lingüistico (19741983), Frankfurt-Madrid: Editorial Iberoamericana / Vervuert. 
Goligorsky, Eduardo (1972): Contra la corriente. Guía de mitos, tabuies y disparates para escépticos, herejes e inconformistas, Buenos Aires: Granica Editor.

Goligorsky, Eduardo (20I8): Comunicación personal vía mail, 2018.

Hernández Busto, Ernesto (200I): «Lolita censurada», Letras Libres, https://www.letraslibres. $\mathrm{com} / \mathrm{mexico-espana/lolita-censurada} \mathrm{[consulta:}$ Io-IX-18].

KING, John (I989): Sur: estudio de la revista literaria argentina y de su papel en el desarrollo de una cultura, I93I-I970, Buenos Aires: Fondo de Cultura Económica.

Lafforgue, Jorge y Jorge B. Rivera (1996): Asesinos de papel. Ensayos de narrativa policial. Buenos Aires: Colihue.

Libardi, Magalí (20I8): "Censorship, Retranslation and Invisibility in the Spanish Edition of Nabokov's Lolita», ponencia presentada en las $\mathrm{V}$ Jornadas Internacionales de Lengua Inglesa de la Universidad del Salvador, https://enedelte. com/censorship-lolita-pezzoni-roca/ [consulta: I4-VIII-I8].

López Castro, Carlos (I96I): «Ejercicio municipal de la policía de costumbres», Lecciones y ensayos (Revista de la Facultad de derecho y Ciencias Sociales, Buenos Aires), 2I-22, I27-I3I.

Lugones, Susana (ig6o): «Entrevista al fiscal: Torquemada, de la Riestra por de la Riestra», Revista Che, I/6, I5 de noviembre de i96o, 21.
Lyons, Martyn (2012): Historia de le lectura y de la escritura en el mundo occidental, trad. Julia Benseñor y Ana Moreno. Buenos Aires: Editoras del Calderón.

Naвокоv, Vladimir (I959): Lolita, trad. Enrique Tejedor, Buenos Aires: Sur.

Pico Estrada, Luis (1959): «El escándalo Lolita en Buenos Aires», Lunes de Revolución, n 35 , noviembre i6 de I959, IO-II.

Rest, Jaime (I967): Literatura y cultura de masas, Buenos Aires: CEAL.

Rest, Jaime (1979): «Marginalidad», en: Conceptos de literatura moderna, Buenos Aires: CEAL, 85-87.

TANzi, Héctor José (2006): «Historia ideológica de la Corte Suprema de Justicia de la Nación (1955I960)», Iushistoria. Revista Electrónica, 3, septiembre, I-I69, www.salvador.edu.ar/juri/reih/index. htm [consulta: I4-VIII-I8].

Tullio, Damián (20I4): «La angustia de la elección imposible: el contexto de la traducción de Lolita de Enrique Pezzoni para la editorial Sur ", Actas VI Congreso Internacional de Letras. Transformaciones culturales. Debates de la teoría, la crítica y la lingüistica, http://cil.filo.uba.ar/sites/cil.filo.uba. ar/files/ui220/TULLIO_D_ACTAS_2OI4.pdf [consulta: Io-IX-I8].

Vila-Sanjuán, Sergio (2oir): Código Best Seller, Madrid: Alianza Editorial.

Willson, Patricia (2004): La Constelación del Sur. Traductores y traducciones en la literatura argentina del siglo XX, Buenos Aires: Siglo xxi Editores. 